www.jmscr.igmpublication.org

Impact Factor (SJIF): 6.379

Index Copernicus Value: 71.58

ISSN (e)-2347-176x ISSN (p) 2455-0450

crossref DOI: _https://dx.doi.org/10.18535/jmscr/v6i4.126

\author{
D) Journal Of Medical Science And Clinical Research \\ IGM Publication \\ An Official Publication of IGM Publication
}

\title{
To Study the influence of Physician's personality type on perception of patient
}

\author{
Author \\ Dr Ananya Omkar Chitale
}

\begin{abstract}
Perceiving is an important aspect in Homoeopathic case taking. According to studies, perception is many times determined by the personality. Hence it is important to understand influence of personality in perceiving patient, his totality and subsequent remedy. Through the review of literature it was found Carl Jung's personality theory to be more complete in itself.

The study was conducted where P.G students were oriented about this study and the volunteers amongst them were given first, the EPI. After analyzing the EPI the physicians were classified into predominantly extroverted and predominantly Introverted Personality types based on their EPI scores. Then the cases taken by them were analyzed on different parameters to study influence of their personality types. Certain Observations were made and analysis was done as mentioned is mentioned prior:

The number of extroverts (74\%) who volunteered for this study was more than the Introverts(26\%). Hence probably as compared to Extroverts the Introverts are usually not open to any process which will demand being introspective and which will subject them to any kind of self assessment. Close or friendly relationships with the patients was formed by most of the physicians $(21$ out of total 30 cases) irrespective of their personality type. Considering the review of literature one doesn't expect Introverts to form very close relationships. But in this study it was found that the personality type doesn't have influenced much in the type of relationship formed.(53.33\% extroverts and $46.67 \%$ Introverts formed close relationships). Such relationships land up the physicians into strong emotional states such as Irritation, rejection, getting sympathized etc. and only in 6 cases the physicians have been able to handle their emotions Hence irrespective of their personality type the physicians have most of the times (24 cases) been unable to overcome their emotions.

The life areas explored by both the personality types, it was found that no significant observations were found as regards to personality type of the PP. The kind of interview skills used by the PPs was also studied. It was found that Extroverts mostly would question (61.53\%) and explore their patients but do minimum of receiving while Introverts were mostly on a receptive mode (81.81\%).. Also there are certain skills otherwise such as role playing, guiding, couselling, empathizing etc were not at all seen in these cases.

Usually we know that two people cannot perceive same patient in a similar manner due to prejudices arising out of our upbringing, past experiences, values etc. In the 30 cases, it was seen that 17 cases were defined by similar personality types out of which in 12 cases the perception came out to be similar of both the physicians irrespective of their background, upbringing and past experiences. Whereas 13 cases were defined by physicians of opposite personality types where only in 4 cases the perception of both PP and observer were same while in 9 cases the perception was different. Also there were 3 cases in which the Introverts were able to overcome their anxieties and emotions as they before going for the case definitions had become consciously aware and had anticipated it. Thus a training to the physicians of formulating a prior problem definition and a process which would make aware about self would help the physicians to overcome the liabilities of their own personality type.
\end{abstract}




\section{Introduction}

Homoeopathy is an intricate science and art. We all homoeopathic physicians are ordinary human beings who through our knowledge, training and experience developed an understanding of the intricacies of the human mind, body, its function in health, and its dysfunction in disease. Just as each patient has their own unique personality, each physician also has their own unique personality or Disposition as we say in Homoeopathy. Hence perceiving of a Human mind has never been standardized and cannot be standardized. Practice of Homoeopathy requires Physicians to understand and perceive every individual Human being in unprejudiced manner the way it travels from health to disease. Many stalwarts in Homoeopathy too have attempted to understand man in health and disease in their own fashion depending on their own disposition or Personality type as we would say in terms of Psychology. But if we understand process of perceiving and how our own personality influences our perception, then it can help us to identify how, when and where do we get prejudiced and how our personality serves as an asset or liability. This truly is first step in journey to evolve as an unprejudiced observer.

\section{Materials and Methods}

Type of Study: Analytical Study.

Source of Data: Patients and M.D. Students from Post Graduate Homoeopathic Institute in Palghar, Maharashtra.

Study Design: It is going to be Cause $\rightarrow$ Effect study, hence is a COHORT study.

Sample:

A) Size of sample: 30 physicians from MLDMHI

B) Sampling method: Random sampling from population of Post graduation students from MLDMHI. who will volunteer for the study.

\section{Method of Collection of Data}

Selecting 30 cases randomly out of which 15 would be by defined by Extroverted Physicians and 15 by introverted physicians.

Specific Tools to be used in the Study:

- Eysenck's Personality Inventory (EPI)

- Clinical Session Evaluation Form (CSEF)

- Life Space

\section{For Sample \\ Inclusion Criteria}

1. Post graduation students from M.L.DMHI of both the sexes.

2. Students who volunteer for the study and who display adequate enthusiasm and commitment to follow the protocols during the study.

\section{Exclusion Criteria}

1. Post Graduate students with any history of or present complaints suggestive of a psychiatric illness (Axis I diagnosis as per DSM-IV TR)

\section{For Cases}

\section{Inclusion criteria}

1. 30 cases of both genders, above $18 \mathrm{yrs}$ of age.

2. Cases with adequate psycho-social data in life-space.

3. Cases which can be managed at OPD basis.

\section{Exclusion criteria}

1. No cooperative patient with psychiatric illness.

\section{Method of study}

1) From all volunteers identifying extrovert physicians and introvert physicians.

2) Considering the cases defined by them.(15 cases by each type)

3) Processing the cases based on following points:

- CSEF (to be filled immediately after case taking)

- Life Areas explored

- Perceiving patient's attributes, mental state

- Approach taken for totality formulation 
- Final totality formulation.

1) Analysis of 15 cases defined by extroverts and 15 cases defined by introverts on above mentioned points.

2) Comparing the results of this analysis so as to understand how these two different personality types receive, perceive and understand the patients.

3) Points of analysis are as follows:

- All points given in CSEF.

- Nonverbal communications.

- Any specific feeling states.

- Life space-Areas explored.

- Perception of mental state.

- Approach taken for totality formation.

- Final totality formation.

\section{Observations and Analysis}

1) Personality Distribution

Table 1: Distribution of Personality Types

\begin{tabular}{|l|c|c|}
\hline Personality types & No. of volunteers & Percentage \\
\hline Extroverts & 25 & $74 \%$ \\
\hline Introverts & 9 & $26 \%$ \\
\hline
\end{tabular}

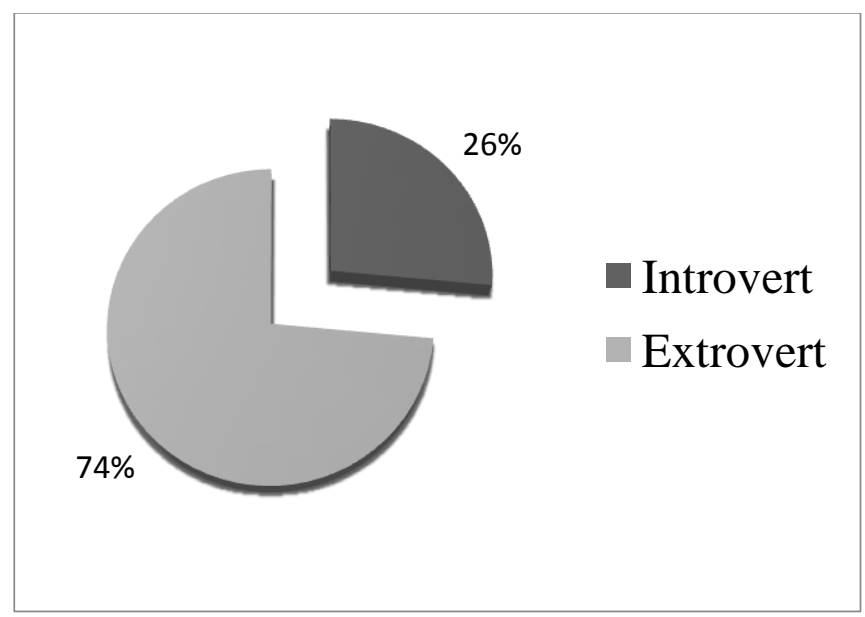

Figure- 1

\section{Observations \& Analysis}

- In the study total 34 physicians had volunteered.

- On EPI analysis it was found that 9 of the total volunteers were predominantly Introverts and 25 out of the 30 volunteers were Predominantly Extroverts.
- Percentage wise $74 \%$ of the total volunteers were Extroverts which is a significant number.

- It is possible that Extroverts are more open for such study.

\section{2) Sex Distribution}

Table 2: Sex Distribution

\begin{tabular}{|l|c|c|}
\hline Personality Type & Male & Female \\
\hline Extroverts & 15 & 3 \\
\hline Introverts & 10 & 6 \\
\hline
\end{tabular}

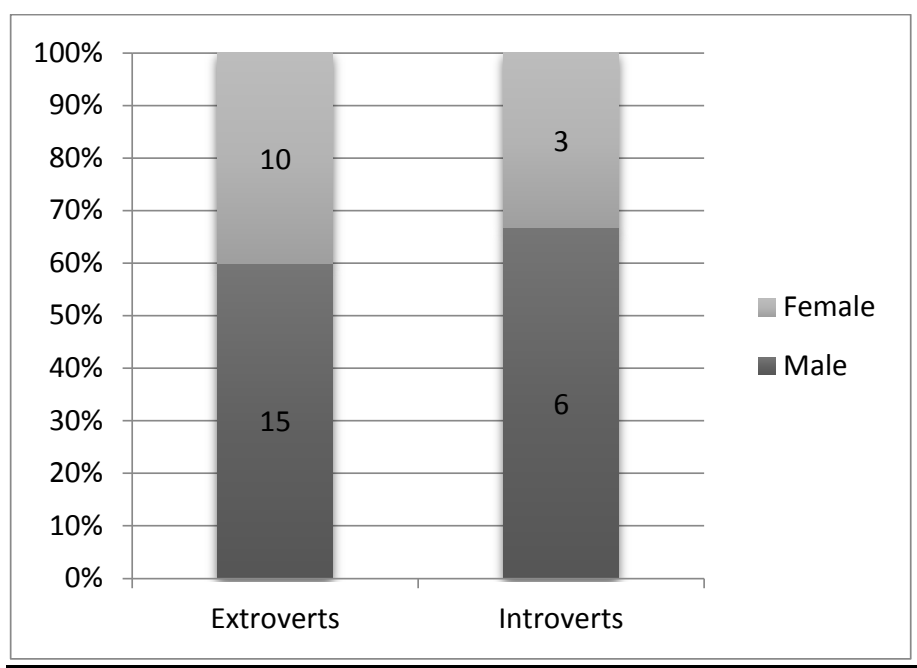

Figure- 2

\section{Observations \& Analysis}

- IN this study total number of male Physicians who volunteered are 18 and total number of females are 16.

- Hence there is not much difference in overall sex ratio.

- Percentage wise amongst Extroverts 60\% are males and $40 \%$ are females.

- Among Introverts there are $33.33 \%$ are female and $66.66 \%$ are males. 


\section{3) Doctor-Patient Relationships}

Table 3

\begin{tabular}{|l|c|c|c|c|c|}
\hline Sr. No & Types of Doctor-Patient relationship & \multicolumn{4}{|c|}{ Total no. times relationship formed } \\
\hline & Extrovert & $\%$ & Introvert & $\%$ \\
\hline 1$)$ & $\begin{array}{c}\text { As a Close Relation e.g. (Mother/Father, } \\
\text { Children, Sister/Brother) }\end{array}$ & 8 & 53.33 & 7 & 46.67 \\
\hline 2$)$ & Friendly & 3 & 50 & 3 & 50 \\
\hline 3$)$ & Professional & 3 & 42.85 & 4 & 57.14 \\
\hline 4$)$ & Undefined Relationship & 1 & 100 & 0 & 0 \\
\hline 5$)$ & Inimical Relationship & 0 & 0 & 1 & 100 \\
\hline
\end{tabular}

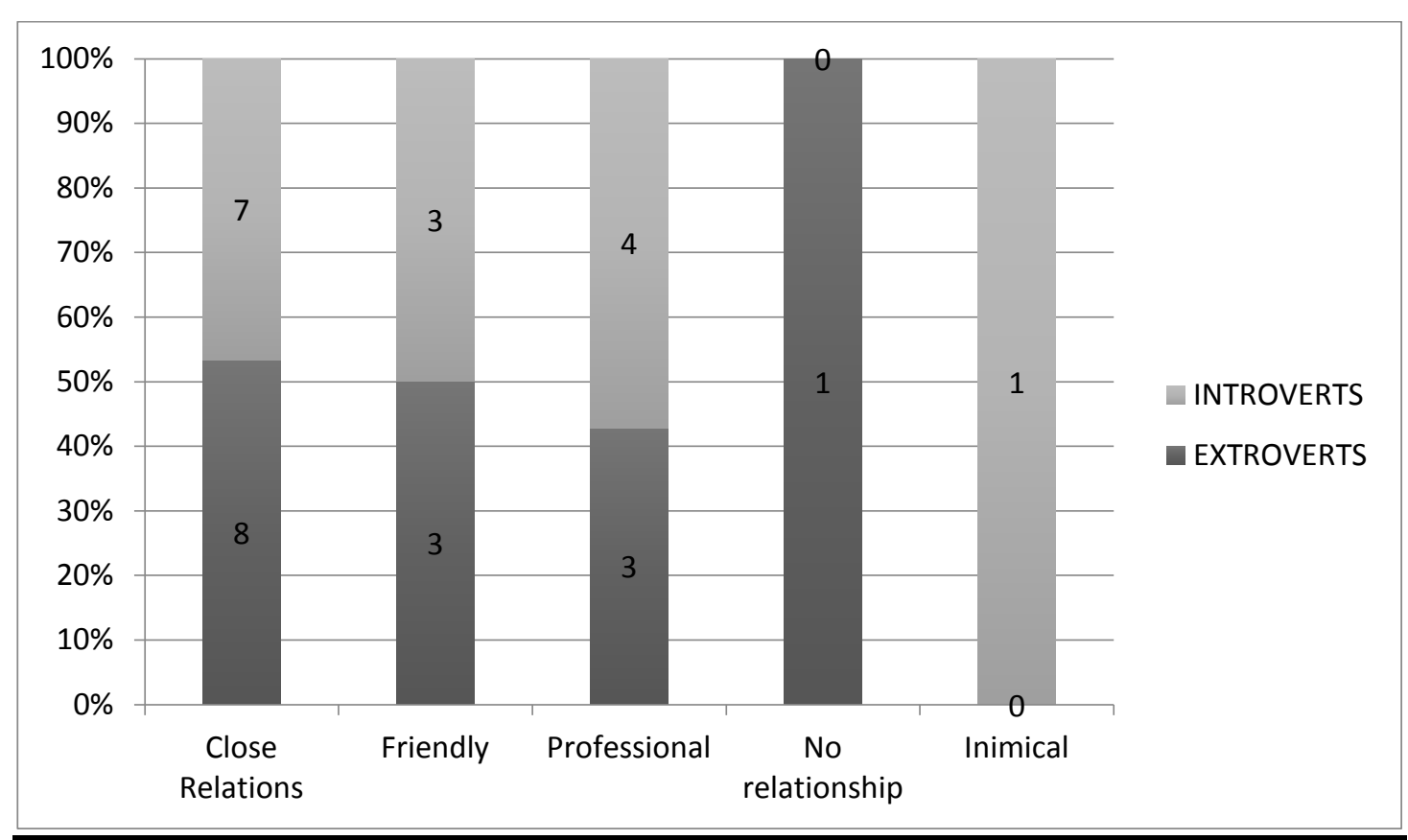

\section{Observations \& Analysis}

- In the 30 cases, most commonly formed Doctor-Patient relationships were close relations such as son/daughter, brother/ sister etc,

- A few were friendly, professional and in one case inimical relationship.

4) Predominant Feeling States of the Physicians

Table- 4: Predominant feeling states

\begin{tabular}{|l|c|c|c|}
\hline Sr. No & Feeling States of physicians & \multicolumn{2}{|c|}{ No. physicians feeling states } \\
\hline & & Extrovert & Introvert \\
\hline 1$)$ & Rejection & 1 & 1 \\
\hline 2$)$ & Identification & 1 & 4 \\
\hline 3$)$ & Getting Impressed & 1 & 4 \\
\hline 4$)$ & Confusion & 1 & 1 \\
\hline 5$)$ & Irritation & 3 & 0 \\
\hline 6$)$ & Neutral & 0 & 0 \\
\hline 7$)$ & Sympathetic & 8 & 3 \\
\hline 8$)$ & Anxious & 1 & 2 \\
\hline
\end{tabular}




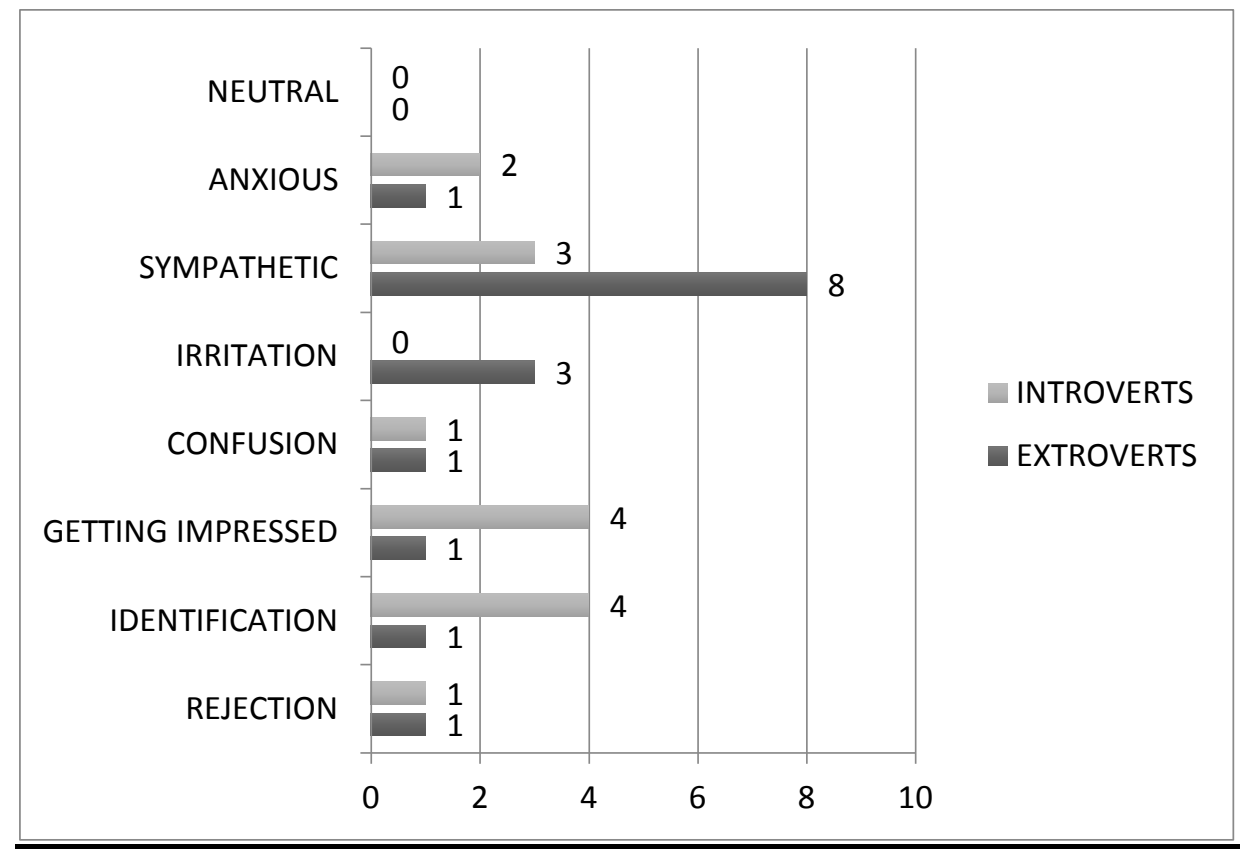

Figure 4

\section{Observation and Analysis}

It is seen that in the case records, that both the personality types have gone through many feeling states, here we considered predominant feeling states.

- The feeling states such as rejection, anxiety, confusion, irritation etc. have been experienced by both personality types without much of a difference. But a neutral state which is an ideal state in the process of interview has not been achieved by either of the personality type.

- The states of sympathy shows apparent predominance in Extroverts and those of Identification and getting impressed show apparent predominance in the Introverts. Hence statistical significance was checked through Chi-square test. The results were as follows: Feeling state Sympathy: The chi-square value for Df-1 under probability of 0.05 is 3.84. The calculated value for chi square is 3.59 which is less and hence under probability for 0.05 is not significant. But if probability under 0.1 the given value is 2.71 and the calculated value is 3.59 which is higher and hence significant at this level. So if this study is considered for a larger sample there are very much chances of significant differences that might come up.

- Feeling states of identification and getting impressed: The Chi-square value for Df-1 under the probability of 0.05 is 3.84 and the calculated value is 0.125 which is less than 3.84 and hence the difference is not significant. But the sample size is too small to conclude upon these feeling states and personality predominance. But considering the difference in number of times such states have come more frequently in Introverts there is chance that a larger sample may show significant influence of personality and feeling states.

5) No. of Times The PP is able to Overcome Feeling States

Table 5: Ability to overcome feeling states

\begin{tabular}{|l|c|c|}
\hline Ability to overcome & Extroverts & Introverts \\
\hline Yes & 3 & 3 \\
\hline No & 12 & 12 \\
\hline
\end{tabular}




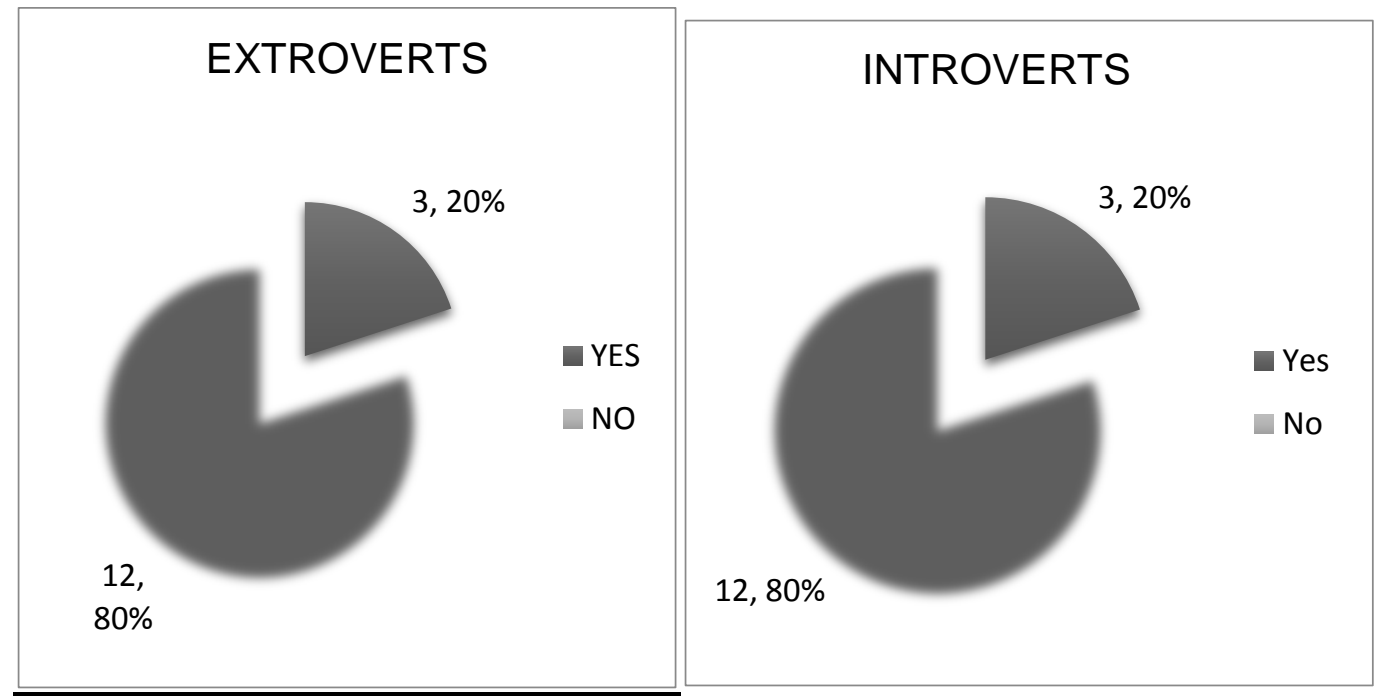

\section{Observations and Analysis}

- It is seen that after developing particular feeling states very few times i.e. only 6 out of 30 times in the cases the physicians have been able to overcome their feeling states and move ahead in the interview.
Figure- 5

- But it is difficult to comment as which personality type has this capacity to overcome their feeling states as in this study, the number is equal for both the personality types. Again a small sample makes it difficult to arrive at a conclusion.

\section{6) Interview Skills}

Table 5: Interview Skills Predominantly used

\begin{tabular}{|l|c|c|c|c|c|}
\hline $\begin{array}{l}\text { Sr. } \\
\text { No. }\end{array}$ & $\begin{array}{c}\text { Types Of Interview Skills } \\
\text { Predominantly used. }\end{array}$ & \multicolumn{4}{|c|}{ Total no. Of physicians } \\
\hline & & Extrovert & $\%$ & Introvert & $\%$ \\
\hline 1$)$ & Receiving/listening & 2 & 18.18 & 9 & 81.81 \\
\hline 2$)$ & Questioning & 8 & 61.53 & 5 & 38.46 \\
\hline 3$)$ & Exploring & 4 & 100 & 0 & 0 \\
\hline 4$)$ & Blocking & 0 & 0 & 1 & 100 \\
\hline 5$)$ & Confrontation & 1 & 100 & 0 & 0 \\
\hline
\end{tabular}

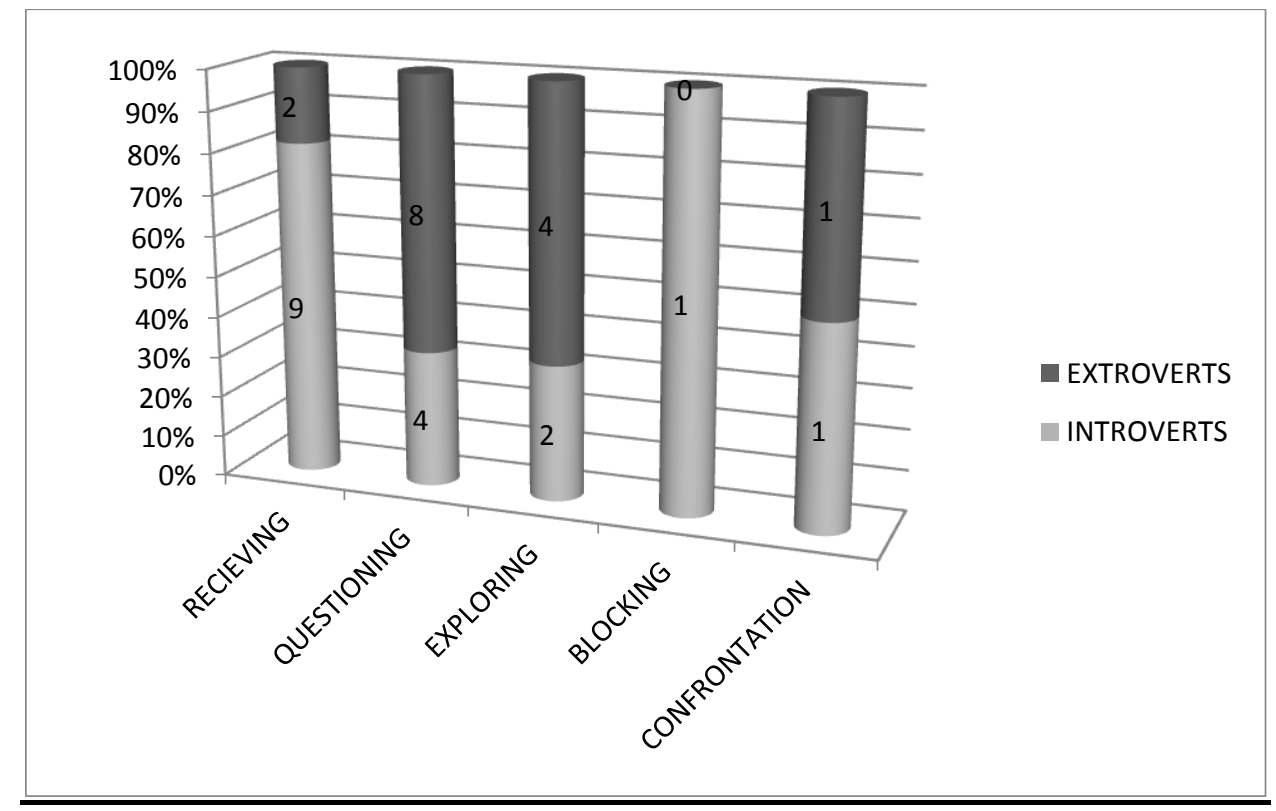

Figure- 6 


\section{Observations and Analysis}

In the 30 interviews the interview techniques used were that of Receiving, Questioning, Exploring, Blocking, Listening, Confrontation. Both the personality types have used multiple skills in each interview, depending on the circumstances, but a predominance of a particular skill was seen in each interview which has been considered here.

- Receiving as an interview skill was often used by Introverts as compared to Extroverts, questioning as an interview skill was more often used by the Extroverted Physicians. As the sample size is small and the data is qualitative to know about its statistical significance Chi Square test was applied as follows:

Interview skill: Receiving. Chi-square value obtained was 7 which is higher than the value of Chisquare for Df- 1 under probability 0.05 is 3.841. hence we can say that the difference in the receiving skill used by both the personality type is significant.

- Questioning.: Chi square value for Df-1 under probability of 0.05 is 3.481 . The calculated value for chi square is 1.22 which is less than 3.481. Hence as far as this study is concerned we cannot say that difference in the questioning skill used by the physicians of different personality types is significant. But for Df- 1 , under probability of 0.5 the value given is 0.46 , and the obtained value is 1.22 which is greater and hence is significant at that level. Hence probably a larger sample may show significant difference.

- The above observations also show that personality types have influenced the other skills also.

- Both of the Personality types have rarely used blocking which can create difficulties for a physician. Introverted physicians have never used exploring as a predominant skill in interview. Extroverts have been very few times in a receiving mode and most of the times questioning the patients. But for a proper and a complete interview a physician irrespective of his personality type must be able to use all these skills rationally so that balance is ensured. The skills such as role playing, guiding, empathizing etc were not at all seen to be used by any of the personality type. Hence it is important for a not only to be aware about his own self and trains himself accordingly so that his personality serves to be an asset and not a liability but also subject him to a training which will develop other skills also.

\section{7) Types of Approaches Used For Totality Formation}

Table 6: Approaches used for totality formation

\begin{tabular}{|l|c|c|c|}
\hline Sr. No. & Type of approach used & \multicolumn{2}{|c|}{ Total no. of physicians } \\
\hline & & Extrovert & Introvert \\
\hline 1$)$ & Kentian & 9 & 12 \\
\hline 2$)$ & Boenninghausen & 2 & 1 \\
\hline 3$)$ & Boger & 0 & 0 \\
\hline 4$)$ & Others & 4 & 2 \\
\hline
\end{tabular}

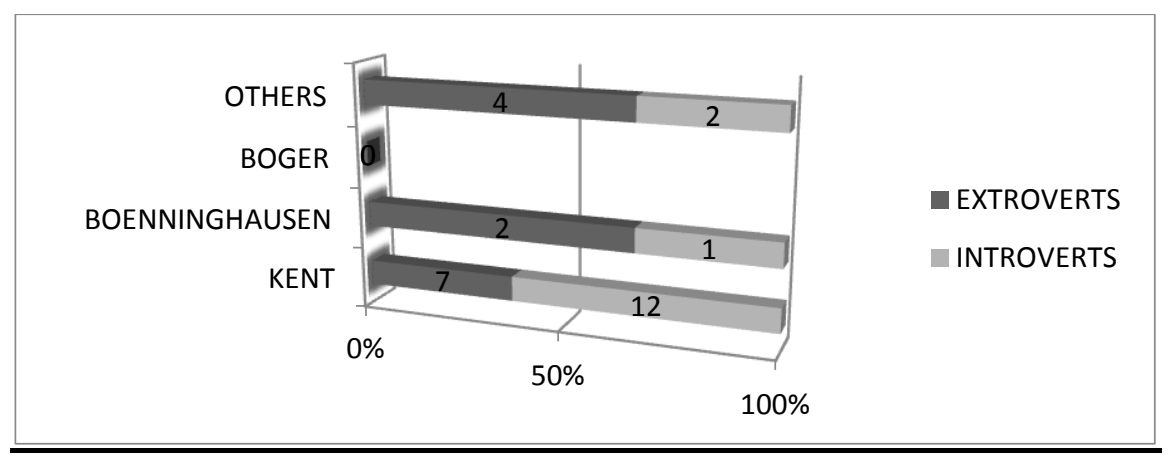

Figure- 7 


\section{Observations and Analysis}

Out of the 30 cases 19 times Kent's Approach was used for totality formation and Introverted Physicians have used this approach more as compared to Extroverted Physicians. On applying Chi Square test the results obtained were as follows:

- The calculated value of Chi square was 3.57. The value given under probability of 0.05 is 3.84 . Hence the difference does not stand significant. But at the probability under 0.5 is 0.46 and the calculated value is greater than 0.46 and hence the difference at that level is significant. Hence there are high chances that in a greater sample there could be more number of introverted physicians using Kent's approach as compared to the Extroverts.

\section{8) Number of Times Personality Predominance Shifts}

\section{Table 8}

\begin{tabular}{|l|c|c|}
\hline & Extroverts & Introverts \\
\hline E- Dominance & 7 & 3 \\
\hline N-Dominance & 8 & 12 \\
\hline
\end{tabular}

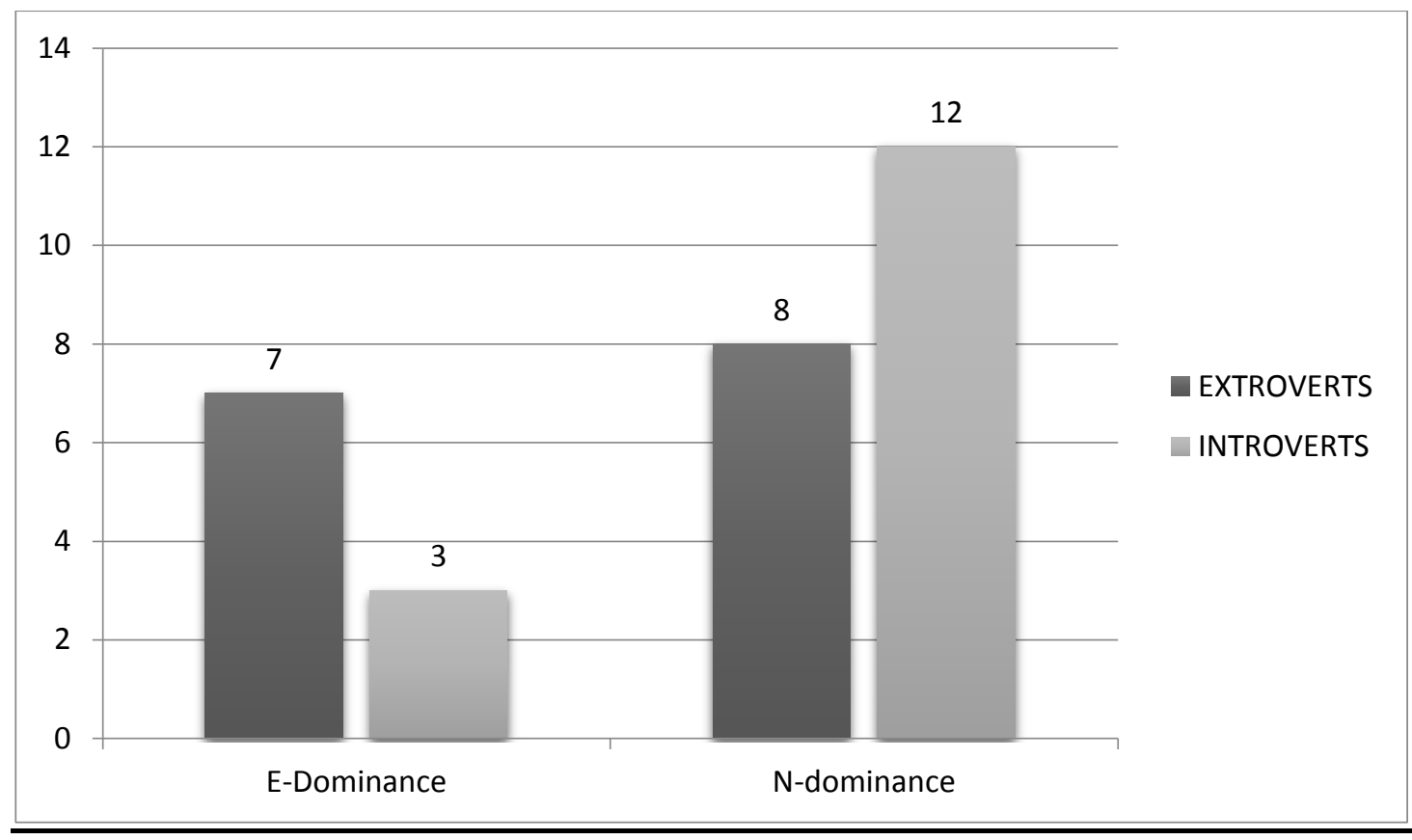

Figure- 8

\section{Observations and Analysis}

Through EPI Analysis of the physician I had knowledge of the predominant personality type of a physician. But in the 30 case records I came across that in certain cases perceiving of the core and totality of patient by the PP has been at a very interpretative and an abstract level, without any strong evidences. This has been seen in case of extroverted physicians too, vice versa was seen in the introverted Physicans who inspite of being predominantly introverted type have been analytical and critical in their case processing. But to understand the statistical significance Chisquare test was applied, and the result obtained was as follows:

- The Chi-square value for Df-1 under probability 0.05 is 3.84 . The calculated value is 3.5 which is less but on considering the Probability at 0.1 which is 2.71 then the calculated value 3.5 is higher. Thus there are very much chances that this study conducted on a larger sample would give significant differences. But one thing that is definitive that 
preferences and predominances in a personality type have potential to mobilize or can get subconsciously mobilized from one particular location, and possibly more often in extroverts.

\section{9) Differences in Perception}

Table 9-a: Pairs and perceptual differences

\begin{tabular}{|l|c|c|c|}
\hline & & \multicolumn{2}{|c|}{ Perception } \\
\hline Pairs & $\begin{array}{c}\text { Number } \\
\text { of cases }\end{array}$ & Similarity & Differences \\
\hline E-E Pairs & 12 & 8 & 4 \\
\hline N-N Pairs & 5 & 4 & 1 \\
\hline E-N Pairs & 13 & 4 & 9 \\
\hline
\end{tabular}

Figure- 9-a-i

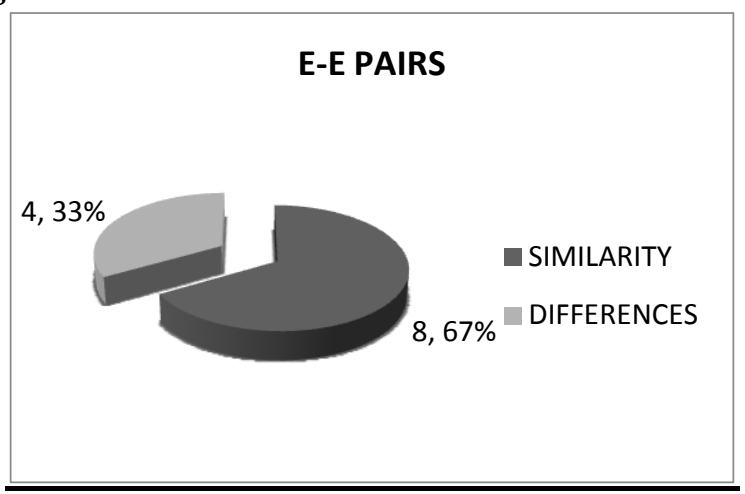

Figure- 9-a-ii

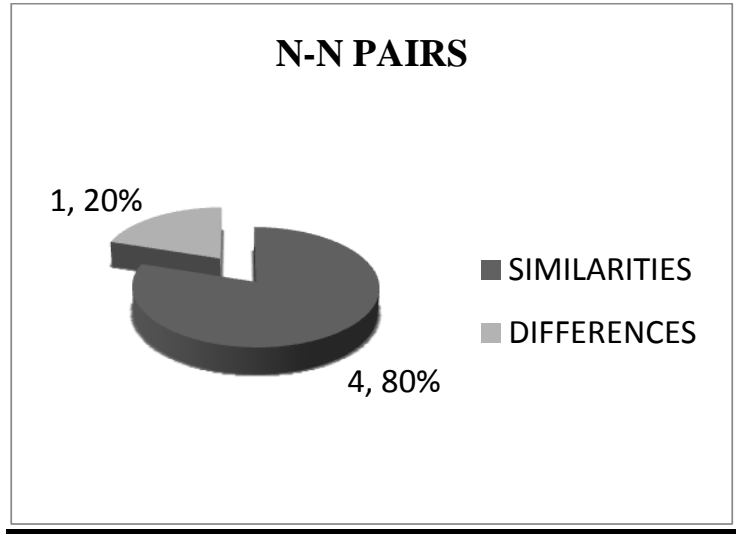

Figure- 9-a-iii

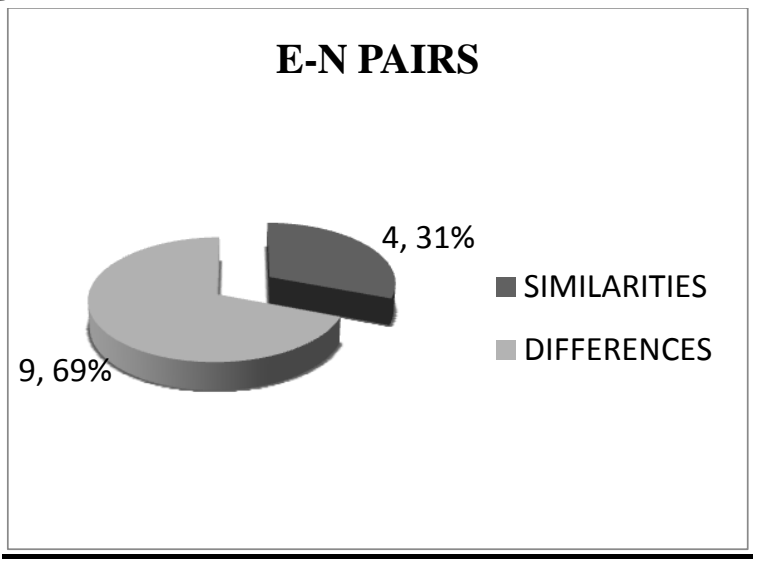

Comparative Aspect of Personality Similarity With Perceptive Similarity

Table-10

\begin{tabular}{|l|c|c|c|}
\hline $\begin{array}{l}\text { Personality } \\
\text { Type }\end{array}$ & $\begin{array}{c}\text { Total number of } \\
\text { cases }\end{array}$ & Similarities & Differences \\
\hline $\begin{array}{l}\text { Similar (E- } \\
\text { E,N-N) }\end{array}$ & 17 & 12 & 5 \\
\hline $\begin{array}{l}\text { Opposite (E- } \\
\text { N) }\end{array}$ & 13 & 4 & 9 \\
\hline
\end{tabular}

Figure- 10-a

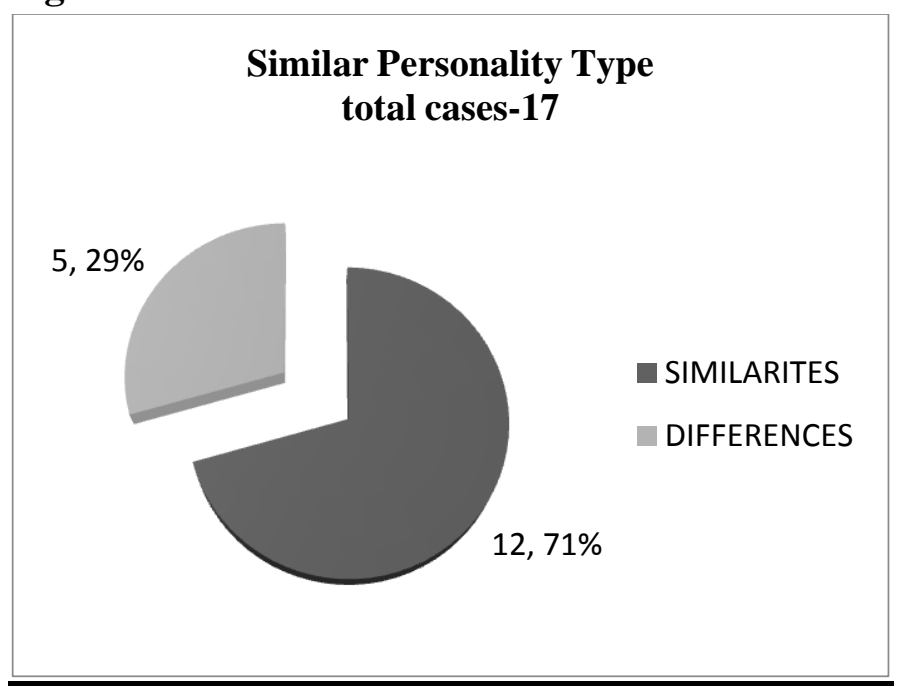

Figure- 10-b

\section{OPPOSITE PERSONALITY TYPE TOTAL CASES-13}

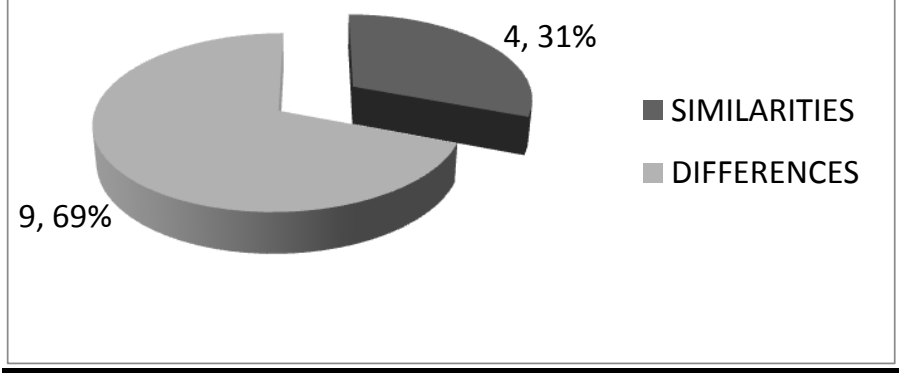

\section{Observations and Analysis}

* On further analysis it is found that although the percentage of similarities and differences is exactly equal but personality types of physicians have been playing the key role leading in these perceptual similarities and differences.

* It was seen that there were total 17 cases out of 30 where both the PP and Observer had similar personality type i.e. either 
Extrovert or Introvert. From these 17 cases it in 12 cases i.e. nearly $71 \%$ cases the outcome was that both PP and Observer have arrived at similar perception of patient as a person and $29 \%$ i.e in 5 cases there were differences in the perception inspite of having similar personality type. The statistical significance of this observation was checked with the help of Chi-Square test. The results were as follows:

- The Chi-square at Df-1 under the probability of 0.05 is 3.84 . The calculated value is 4.66 which is greater than 3.84 hence the difference is significant. Thus we can definitely conclude that definitely when 2 dissimilar personalities perceive patient they arrive at different perception more often as compared to similar personality type.

\section{Discussion}

1) Out of the M.D students in Post Graduate, Homeopathic Medical College and Hospital it was seen that 34 of them volunteered for this study. Out of them 25 physicians were found to be predominantly extroverted type and 9 were found to be predominantly introverted type on EPI analysis. This kind of studies demand a will to get reflective as well as be open to a particular assessment of self. As regards to the understanding of personality types it has been observed that Extroverts are usually more adventurous experimentative as copmpared to Introverts who are known to be basically of close nature and usually prefer to be aloof. The figures seen in this study as possibly indicate the same thing that Extroverted people are more open to this kind of studies as compared to Introverts.

2) As far as the sex distribution is concerned it was found that number of males participated in the study was higher than females. And as far as the personality type in both the genders is concerned not much difference was found except for the fact that in general number of extroverts in both the genders was more than the number of introverts from both genders. Also we can say that probably females do not show much interest in such kind of analytical studies.

3) The kind of doctor patient relationship formed by the different physicians was analysed and it was seen that both the personality types have been able to form a wide range of relationship irrespective of their predominant personality type. The relationships more often formed were close relationships like father, mother, sister, son, daughter etc. (in 8 cases extroverts and 7 cases by introverts). While the other relations formed were friendly, professional etc. but the difference as regards to personality type was not significant.

4) PP in the case taking have used different types of interview skills. It was seen that out of 15 cases defined by Extroverts in 8 cases the extroverts have used the skills of Questioning whereas in introverts it was seen only in 5 case. Exploration was done in 4 cases by Extroverts but not a single case by Introverts. But Introverts had used the skill of receiving in 9 cases as compared to extroverts who utilized them predominantly in only 2 cases out of 15 .

5) It was found that all the physicians irrespective of their personality type underwent a strong mental state. The different feeling states that were seen in the physicians were those of Sympathy, rejection, Irritation, getting impressed, Identification etc. But certain feeling states were seen to be occurring more frequently in a particular personality type. In 8 cases out of 15 Extroverts were seen to get sympathized with the patients and Getting impressed and Identification with the patient was seen more in Extroverted physicians. Where as Introverted types had got impressed or 
identified more often as compared to the Extroverted Physicians. But for establishing the statistical significance a large sample is required.

6) As seen earlier all the physicians underwent a strong feeling state during the interview. But what is more important is ability to overcome such states. This was seen in less number. i.e out of total 30 cases only 6 times the physicians were able to overcome the states to some extent whereas 24 were not. But it was seen that there was no difference as regards to number of times each of the personality was able to overcome their feeling states and vice versa.

7) As far as the approach was concerned it was seen that Kentian approach was used for 21 cases with introverted using it in 12 cases and extroverts in 9 cases. Other approaches such as structuralisation was also used more often by Extroverts. But Boger's approach was not seen in any of the case. The reason for this was that most of the physicians lacked knowledge about this concept. Kentian concept was considered more often as most of the physicians had been interpretative in approach and hence mental symptoms were given more importance. This was seen more often in Introverts who utilized this approach in 12 cases out of 15 .

8) In the 30 case records another finding was different physicians behaved in different manner during the case taking at times contrary to their personality type which was available to us through EPI analysis. There were 8 cases in which the extroverts have been displaying introverted features such as getting anxious, irritated, getting influenced easily etc. In these PPs it was found that there $\mathrm{N}$ score was also on a higher side as compared to the other Extroverted physicians. Then there were 3 cases out of 15 where Introverted PPs displayed extroverted features such as going into details, being analytical etc. These PPs were consciously aware of their possible states which might create difficulties and hence had tried to remain focused.

Lastly a comparison was done as regards to what are the chances of perceptual differences when 2 physicians of same or opposite personality type perceive the same patient. Then it was found that the differences that arise when two opposite personality type perceive the patient are much more as compared to the situation where similar personality type perceive the patient.

\section{Conclusion}

It is seen through the study that the personality of the physician influences his process of perception and final patient understanding at multiple levels.

It is seen from the study that Physicians personality is very much responsible for the manner in which he is going to perceive his patients.

The conclusions drawn in this study gives us an understanding of following important facts:

1) It is seen from the study that Physicians personality is very much responsible for the manner in which he is going to perceive his patients but it is not very clear in all perspectives due to smaller sample size.

2) Irrespective of the personality type it has been seen that certain Physicians have been able to stabilize themselves emotionally, have been analytical, and were fairly objective. As mentioned in the The Introverts and the Extroverts both have functions such as Thinking, Intution, feeling, judging etc. The dominance of any of these will again influence perception of the patient.

3) Most importantly is any homoeopathic physician need to be aware of his personality type, his sensitivities, its advantages and disadvantages so that he can be objective as far as possible. 


\section{References}

1. Close Stuart (2005) The Genius of Homoeopathy Lectures and Essays on Homoepathic Philosophy, chapter 1- The Psychological Point Of View. B. Jain Publishers Pvt. Ltd, New Delhi.

2. Dhawale M.L (1994) Hahnemannian Totality Symposium VOL 1 AREA B2, Publication: Institute of clinical research Bombay.

3. Dudgeon R. E., (2004) The Lesser Writings of Samuel Hahnemann The Medical Observer (1825) Reprint Edition, Publications: B.Jain Publishers Pvt Ltd, New Delhi

4. Hahnemann Samuel, (2001) Organon of medicine $5^{\text {th }} \& 6^{\text {th }}$ edi., Publishers- IBPP.

5. Jung, C.G., ([1921] 1971). Psychological Types, Collected Works, Volume 6, Princeton, N.J.: Princeton University Press

6. Kaplan \&Saddock, (1985) A comprehensive textbook of psychiatry, Chapter 9 Personality and psychopathology: Cultural and Interpersonal Psychoanalytic schools Seventh edition, William and Wilkins U.S.A

7. Kent J. T., (2002) Lectures on homoeopathic philosophy, lecture-5 Publication: B. Jain Publishers Pvt Ltd, New Delhi.

8. Rummel R. J., (1975) Understanding conflict and war: vol. 1: the dynamic psychological field, Chapter 7, Perception and Reality. Sage Publications, California

9. Wansbrough C. J., The Homoeopath, No.61 1996. Publisher C.J.Wansbrough

10. Whitmont Edward, (1969) The Symbolic Quest, Chapter 3 The Objective Psyche Publication: G.P Putnam's Sons, New York.

11. Whitmont Edward, (1986) Psyche \& Substance, Indian Books and Periodicals Syndicate, New Delhi. 